\title{
Análise comparativa entre esclera tratada com glicerina e esclera tratada com irradiação gama, álcali e glicerina em reconstrução de cavidade anof tálmica: estudo experimental em coelhos
}

\author{
Comparative analysis between sclera treated with glycerin and sclera treated with \\ gamma irradiation, alkali and glycerin in the reconstruction of anophthalmic socket: \\ experimentalstudy in rabbits
}

\author{
José Byron Vicente Dias Fernandes ${ }^{1}$ \\ Suzana Matayoshi ${ }^{2}$ \\ Junko Takano Osaka ${ }^{3}$ \\ Erasmo Castro Magalhães Tolosa ${ }^{4}$ \\ Tânia Pereira Nunes ${ }^{5}$ \\ Eurípedes da Mota Moura ${ }^{6}$
}

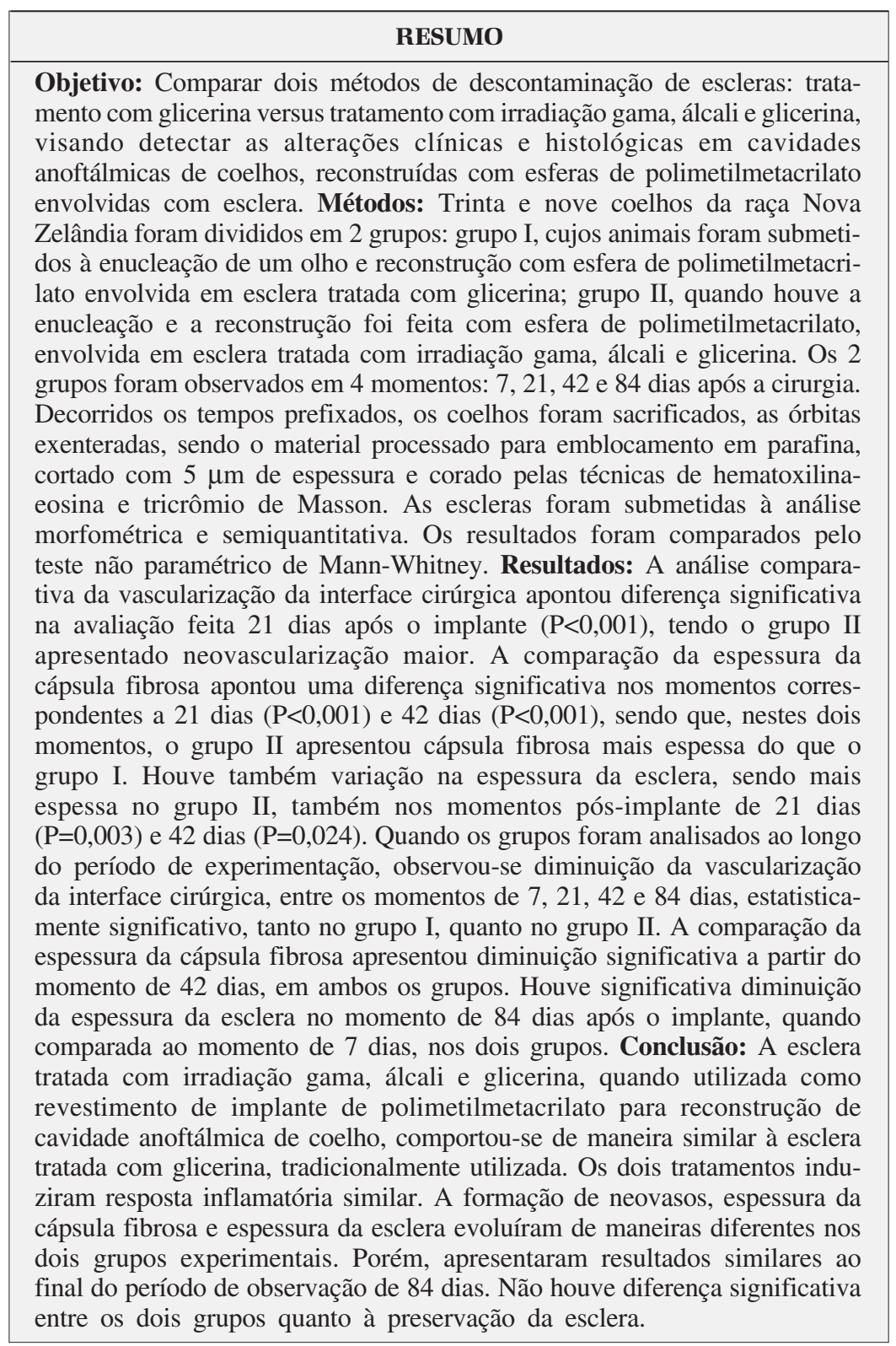

Descritores: Esclera; Esclera/efeitos de radiação; Descontaminação; Enucleação ocular;

Implantes orbitários; Glicerol; Polimetilmetacrilato; Estudo comparativo; Coelhos

Objetivo: Comparar dois métodos de descontaminação de escleras: tratamento com glicerina versus tratamento com irradiação gama, álcali e glicerina, vetectar as alterações clínicas e histológicas em cavidades envolvidas com esclera. Métodos: Trinta e nove coelhos da raça Nova lato envolvida em esclera tratada com glicerina; grupo II, quando houve a enucleação e a reconstrução foi feita com esfera de polimetilmetacrilato, grupos foram observados em 4 momentos: 7, 21, 42 e 84 dias após a cirurgia. Decorridos os tempos prefixados, os coelhos foram sacrificados, as órbitas eosina e tricrômio de Masson. As escleras foram submetidas à análise morfométrica e semiquantitativa. Os resultados foram comparados pelo tiva da vascularização da interface cirúrgica apontou diferença significativa na avaliação feita 21 dias após o implante $(\mathrm{P}<0,001)$, tendo o grupo II pondentes a 21 dias $(\mathrm{P}<0,001)$ e 42 dias $(\mathrm{P}<0,001)$, sendo que, nestes dois momentos, o grupo II apresentou cápsula fibrosa mais espessa do que o $(\mathrm{P}=0,003)$ e 42 dias $(\mathrm{P}=0,024)$. Quando os grupos foram analisados ao longo do período de experimentação, observou-se diminuição da vascularização

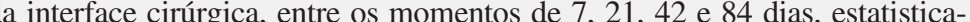
espessura da cápsula fibrosa apresentou diminuição significativa a partir do comparada ao momento de 7 dias, nos dois orupos. Conclusão: A esclera tratada com irradiação gama, álcali e glicerina, quando utilizada como te tratada com glicerina, tradicionalmente utilizada. Os dois tratamentos induziram resposta inflamatória similar. A formação de neovasos, espessura da cápsula fibrosa e espessura da esclera evoluíram de maneiras diferentes nos final do período de observação de 84 dias. Não houve diferença significativa entre os dois grupos quanto à preservação da esclera.

\footnotetext{
Trabalho realizado no Departamento de Oftalmologia e Otorrinolaringologia da Disciplina de Técnica Cirúrgica e Cirurgia Experimental da Faculdade de Medicina da Universidade de São Paulo - USP e no Laboratório de Patologia do InCor - Hospital das Clinicas, Faculdade de Medicina. Universidade de São Paulo - USP São Paulo (SP) - Brasil.

Pós-graduando, doutorado, Faculdade de Medicina da Universidade de São Paulo - USP - São Paulo (SP) Brasil.

Assistente doutora, Hospital das Clinicas, Faculdade de Medicina. Universidade de São Paulo - USP - São Paulo (SP) - Brasil.

Farmacêutica Bioquímica, Faculdade de Medicina. Universidade de São Paulo - USP - São Paulo (SP) - Brasil. Professor Titular da Disciplina de Técnica Cirúrgica e Cirurgia Experimental Faculdade de Medicina. Universidade de São Paulo - USP - São Paulo (SP) - Brasil. Pós-graduanda, doutorado, Faculdade de Medicina da Universidade de São Paulo - USP - São Paulo (SP) Brasil

Assistente doutor, Hospital das Clinicas, Faculdade de Medicina. Universidade de São Paulo - USP - São Paulo (SP) - Brasil.

Endereço para correspondência: José Byron Vicente Dias Fernandes. Rua Alves Guimarães, 1317 - Apto.73 - São Paulo (SP) CEP 05410-002

E-mail: josebyron@ig.com.br

Recebido para publicação em 10.03.2006

Última versão recebida em 07.05.2007

Aprovação em 10.05.2007

Nota Editorial: Depois de concluída a análise do artigo sob sigilo editorial e com a anuência da Dra. Silvana Artioli Schellini sobre a divulgação de seu nome como revisora, agradecemos sua participação neste processo.
} 
640 Análise comparativa entre esclera tratada com glicerina e esclera tratada com irradiação gama, álcali e glicerina em reconstrução de cavidade anoftálmica: estudo experimental em coelhos

\section{INTRODUCÃO}

A esclera homóloga teve seu uso consagrado em oftalmologia a partir da década de cinqüenta, quando foi utilizada como revestimento de implantes em cavidade anoftálmica, sendo também, empregada em outros procedimentos oftalmológicos ${ }^{(1)}$.

O sucesso da utilização da esclera homóloga no revestimento de implantes em cavidades anoftálmicas está associado ao fato de integrar-se aos tecidos adjacentes e provocar pouca reação inflamatória local.

Embora a esclera seja considerada um excelente material, cuidados específicos devem ser tomados no seu uso em relação à contaminação inicial do tecido e à eficiência dos métodos para sua descontaminação ou esterilização. A maioria dos olhos doados alberga microorganismos em sua superfície, principalmente bactérias ${ }^{(2-4)}$. A triagem de doadores de olhos para organismos patogênicos, doenças neurológicas de origem desconhecida, linfomas, leucemias, causa mortis desconhecida está bem estabelecida. Organismos como príons (que não são detectáveis em portadores assintomáticos) ou outros agentes infecciosos (que não estão previstos na triagem por desconhecimento de seu potencial patogênico) devem ser alvo de preocupação da comunidade científica, devido à possibilidade de transmissão iatrogênica.

Os príons são altamente resistentes à inativação pelos desinfetantes comuns, exigindo procedimentos específicos de descontaminação. Soluções de hipoclorito de sódio ou hidróxido de sódio podem ser eficientes, dependendo da concentração, mas têm como fator inconveniente a sua natureza corrosiva ${ }^{(5-6)}$. Procedimentos de inativação física por ultravioleta ou irradiação ionizante podem não ser completamente eficientes para a inativação dos príons ${ }^{(7)}$.

A glicerina tem sido tradicionalmente utilizada como preservante para a esclera, estocada em temperatura ambiente, sendo, porém, inócua para a inativação de alguns organismos contaminantes $^{(8)}$, como o Herpes vírus que já foi isolado de esclera estocada em glicerina ${ }^{(9)}$ e o HIV que foi detectado na esclera de pacientes soropositivos ${ }^{(10)}$. Também algumas bactérias podem sobreviver em esclera preservada em glicerina por alguns dias ${ }^{(11-12)}$.

Os métodos de preservação da esclera utilizados em nosso meio (glicerina ou álcool), não são eficientes contra os vírus e os príons. A associação de tratamento químico e físico parece ser a forma mais segura para a eliminação de agentes infecciosos não convencionais, como os príons.

É importante considerar também que o método de esterilização/descontaminação, usados na manipulação de tecidos, não danifique suas propriedades estruturais, o que poderia prejudicar a função para o qual está sendo proposto o seu uso. Trata-se, portanto, de combinar um método de preservação da esclera, que tenha a máxima capacidade de eliminação de agentes patógenos, sem destruir o tecido.

Desta forma, o presente estudo foi delineado, usando animais de experimentação que foram enucleados e que receberam implantes de polimetilmetacrilato (PMMA), revestidos por esclera preservada de duas formas diferentes: por glicerina ou por irradiação gama combinada com álcali e glicerina, com o objetivo de comparar estes métodos de preservação.

\section{MÉTODOS}

Foram utilizados 39 coelhos da raça Nova Zelândia, brancos, machos, pesando aproximadamente 3 quilogramas, com idade aproximada de 2 a 3 meses, provenientes do Centro de Bioterismo da FMUSP. Todos os procedimentos descritos para a manipulação dos animais, estão de acordo com as normas éticas indicadas internacionalmente (NRC, 1996) ${ }^{(13)}$ e foram aprovadas pela Comissão de Pesquisa e Ética do HCFMUSP (Protocolo de pesquisa 194/04).

Os coelhos foram divididos em dois grupos:

- Grupo I: animais submetidos à enucleação de um olho e reconstrução com esfera de PMMA (polimetilmetacrilato) envolvida em esclera tratada com glicerina $(n=19)$.

- Grupo II: animais submetidos à enucleação de um olho e reconstrução com esfera de PMMA envolvida em esclera tratada com irradiação gama, álcali e glicerina $(n=20)$.

As escleras destinadas aos coelhos do grupo I foram mantidas em frasco contendo glicerina a $98 \%$, à temperatura ambiente, respeitando-se o tempo mínimo de 15 dias e máximo de 45 dias para a utilização.

As escleras destinadas aos coelhos do grupo II foram submetidas a tratamento enzimático, para remover todas as células, debris não colagenosos, lipídeos e depósitos de gordura; imersão em solução $0,1 \mathrm{M}$ de $\mathrm{NaOH}$, por 1 hora, e inúmeros procedimentos de lavagem com solução fisiológica entre as etapas descritas. As escleras foram então imersas em glicerina a 98\%, embaladas em envelope duplo de polietileno, fechados separadamente por selagem eletrônica. Estes procedimentos foram realizados pela Mackron Biopolímeros Indústria e Comércio Ltda. (Mogi das Cruzes, SP). Em seguida, foram encaminhadas para esterilização por $25 \mathrm{kGy}$ de radiação gama (Embrarad, Cotia, SP), permanecendo à temperatura ambiente.

Animais de ambos os grupos foram seguidos e sacrificados em 4 momentos: 7, 21, 42 e 84 dias após a cirurgia. Após o sacrifício, procedeu-se a exenteração orbitária, sendo o material preparado para análise histológica.

Amostras das escleras dos grupos I e II foram encaminhadas ao Laboratório de Bacteriologia do Biotério Central do Instituto de Ciências Biomédicas da USP. Em capela de fluxo laminar escleras inteiras foram colocadas assepticamente sobre placas de Petri contendo ágar sangue a 5\%. Após 48 horas de incubação a $37^{\circ} \mathrm{C}$, as placas foram examinadas.

Foram utilizados 5 coelhos, considerados como doadores, para a obtenção de escleras de revestimento, sendo os animais anestesiados, usando $35 \mathrm{mg} / \mathrm{kg}$ de ketamina e $5 \mathrm{mg} / \mathrm{kg}$ de xilazina, administrados por via endovenosa. Para o sacrifício, utilizou-se $5 \mathrm{ml}$ de cloreto de potássio $(\mathrm{KCl} 19,1 \%)$ endovenoso. Posteriormente, as contralaterais obtidas nos respectivos mo- 
mentos de sacrifício, foram aproveitadas como revestimento.

Além das escleras coletadas para serem submetidas aos tratamentos acima, foram coletadas também escleras que não receberam qualquer tratamento prévio para serem analisadas como padrão de normalidade. Esses espécimes, submetidos aos três tipos de procedimentos, foram preparados para avaliações histológica e ultra-estrutural para identificação de possíveis alterações (vide quadro sinóptico).

\section{OUADRO SINÓPTICO}

Para o procedimento cirúrgico, os coelhos permaneceram por um período de 48 horas no Biotério de Experimentação, da Disciplina de Técnica Cirúrgica e Cirurgia Experimental da FMUSP, para adaptação, foram anestesiados com $35 \mathrm{mg} / \mathrm{kg}$ de ketamina e $5 \mathrm{mg} / \mathrm{kg}$ de xylazina, endovenoso. Além da anestesia geral, foi infiltrado $0,5 \mathrm{~mL}$ de xilocaina a $2 \%$ no espaço retrobulbar (agulha $23 \mathrm{G}$ ), e instilação de uma gota de colírio de tetracaína $0,5 \%$ e uma gota de colírio de tobramicina $0,3 \%$.

As escleras utilizadas como revestimento do implante foram retiradas dos frascos de glicerina ou do envelope duplo utilizado para embalagem das escleras irradiadas, e rehidratadas com solução fisiológica a $0,9 \%$, por um período de 30 minutos, à temperatura ambiente. As esferas de PMMA de $10 \mathrm{~mm}$ de diâmetro (Pinheiro Prótese, São Paulo) foram recobertas com as escleras, utilizando-se sutura com pontos em "U" separados, com nylon 6.0.

Foi observada a seguinte sequiência: assepsia e anti-sepsia com povidine a $1 \%$; colocação de blefarostato; peritomia límbica $360^{\circ}$ com tesoura; apreensão dos músculos extrínsecos e secção na inserção; secção do nervo óptico com tesoura; colocação do implante já preparado na cavidade orbitária com a sutura de nylon voltada para a região do fundo da órbita (Figura 1); sutura da conjuntiva com Vycril 6.0, com pontos separados; instilação de uma gota de tobramicina $0,3 \%$.

Os coelhos foram observados nos momentos pós-operatórios de 7, 21, 42 e 84 dias. Duas vezes por semana era

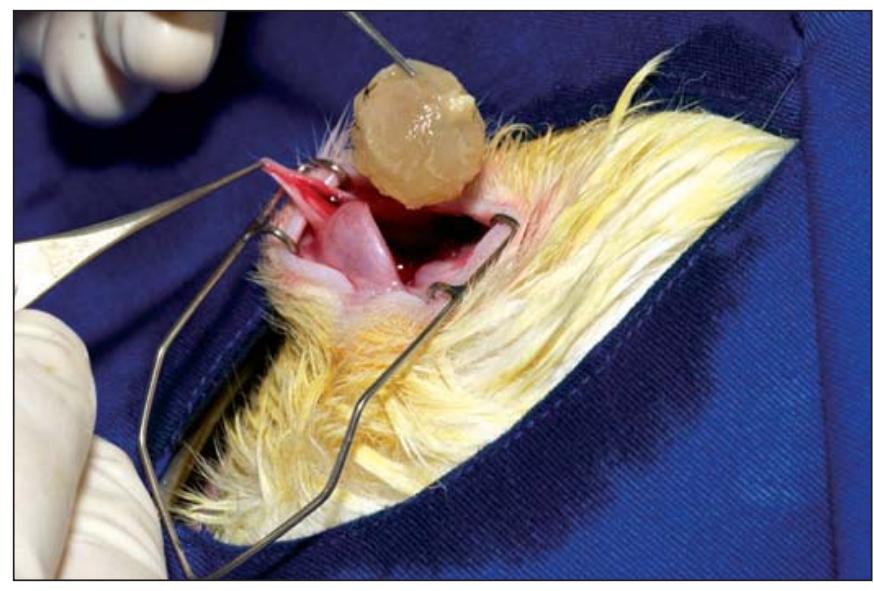

Figura 1 - Colocação do implante já preparado na cavidade orbitária realizada uma avaliação ectoscópica para avaliar eventuais intercorrências.

Nos momentos padronizados, os coelhos foram sacrificados conforme descrito acima. As órbitas foram exenteradas, seccionadas em 2 metades com corte passando perpendicularmente ao comprimento das pálpebras superior e inferior no sentido ântero-posterior (buscando aproximar-se da região central do implante), colocadas em formol tamponado a $10 \% \mathrm{e}$ processadas para emblocamento em parafina, cortadas com $5 \mu \mathrm{m}$ de espessura e coradas pelas técnicas de hematoxilinaeosina e tricrômio de Masson.

A análise semiquantitativa foi realizada por dois observadores independentes, que desconheciam a origem das amostras, em microscópio óptico (Modelo DMLB, Leica, Inglaterra), analisando o estado de preservação da esclera e o infiltrado inflamatório, atribuindo-se os seguintes escores: preservação da esclera $(0=$ ausente; $1=$ afinamento pronunciado das fibras de colágeno; 2 = afinamento discreto das fibras de colágeno; $3=$ fibras de colágeno bem preservadas) e infiltrado inflamatório $(0=$ ausente $; 1=$ pequeno $; 2=$ moderado $; 3=$ grande $)$, analisados em dez campos da região anterior e dez campos da região posterior, aleatoriamente, utilizando-se a lente de 40 aumentos.

A análise quantitativa da espessura da esclera e da espessura da cápsula fibrosa foi feita em um analisador de imagem digitalizada Leica QWIN Standard para medições manuais e automáticas, incluindo filtros de estruturas por forma, cor e tamanho, versão 2.4, 2001 (Microsystems Imaging Solutions Ltd., Cambridge, Inglaterra), da Anatomia Patológica do Instituto do Coração - InCor, FMUSP, coletando-se a largura da esclera e da cápsula fibrosa em vinte pontos aleatórios, com objetiva de cinco aumentos e a unidade de medida em micrômetro $(\mu \mathrm{m})$.

O número de neovasos na cápsula fibrosa ao redor do implante foi quantificado, adotando-se como valor final, a mediana do número de neovasos presentes em dez campos analisados, tanto na região anterior como posterior.

Para análise morfológica e ultra-estrutural foram coletadas amostras de escleras sem tratamento, escleras preservadas em glicerina e escleras tratadas por irradiação gama, hidróxido de sódio e glicerina. Os espécimes foram fixados em formol tamponado a $10 \%$ e processados conforme descrito acima; quando destinados à análise histológica e glutaraldeído a 3\%, para a avaliação ultra-estrutural, com emblocamento em moldes flexíveis de silicone contendo resina. A partir da observação e análise ao microscópio óptico de cortes semifinos foram selecionados os blocos mais representativos para o corte ultrafino a 60-70 nm de espessura para posterior observação ao microscópio eletrônico de transmissão Philips Tecnai.

Os resultados das medianas das análises semiquantitativas e quantitativas foram submetidas ao procedimento analítico estatístico, pelo programa Sigma Stat para Windows, versão 2,0 (Sigma Chemical, Co, St Louis, MO, EUA). Adotou-se o teste não paramétrico de Mann Whitney, realizando sempre a comparação entre os grupos I e II, dentro de cada período pós-operatório. Os valores de $\mathrm{P}<0,05$ foram considerados estatisticamente significativos. 


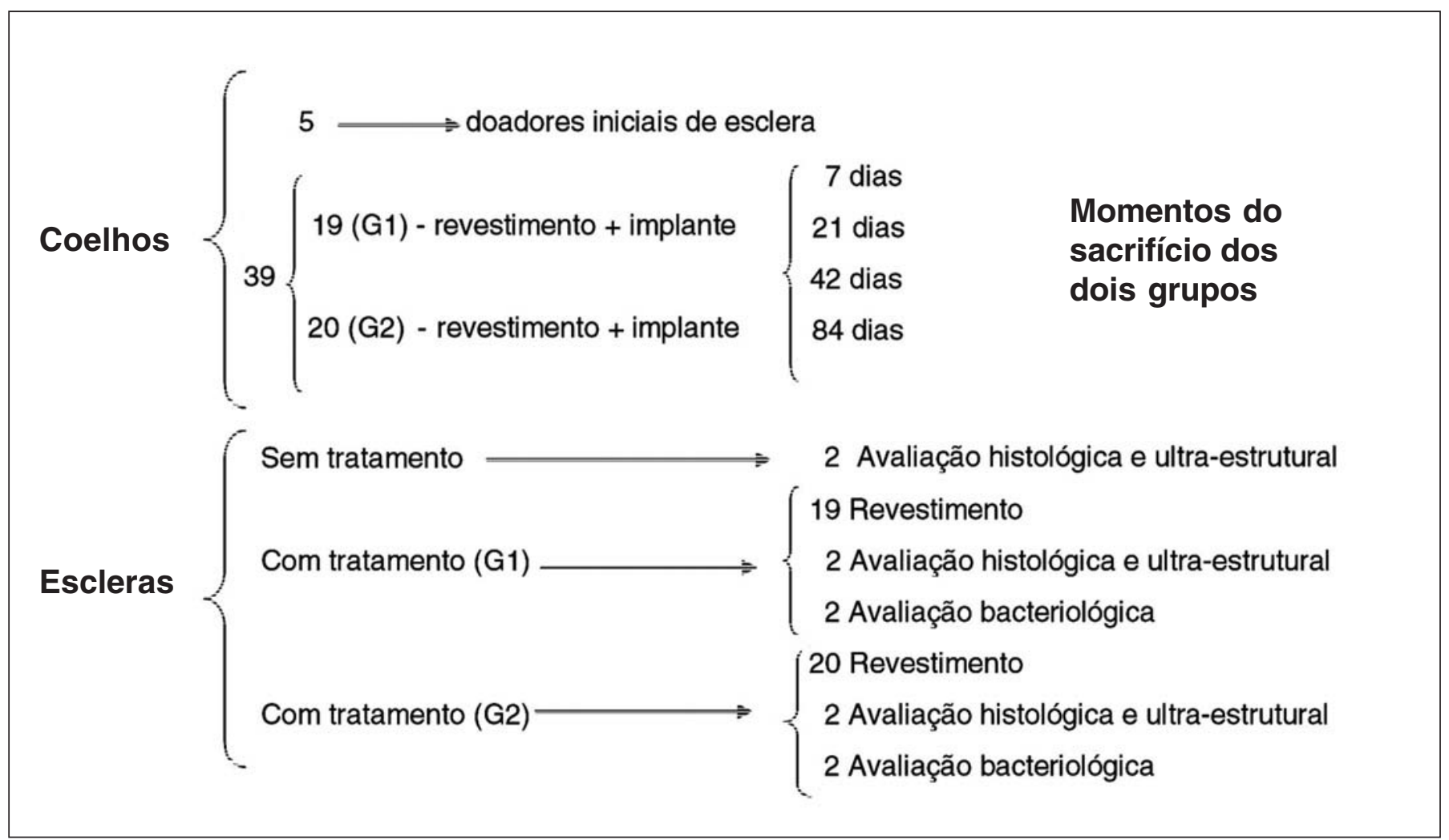

Quadro sinóptico - Desenho do estudo

\section{RESULTADOS}

Os testes de validação da descontaminação bacteriológica das escleras dos grupos I e II resultaram em ausência de crescimento de bactérias, em um meio rico como ágar sangue que possibilita o crescimento tanto de bactérias Gram negativas como positivas.

Os procedimentos cirúrgicos ocorreram sem intercorrências nos 2 grupos. Notou-se entretanto, que no preparo do implante, as escleras do grupo II apresentavam-se mais friáveis à manipulação, com tendência a esgarçamento, o que acarretou um tempo um pouco maior na execução dessa etapa.

Durante todo o período de observação pós-operatória os animais apresentaram-se com as funções fisiológicas normais e bom estado geral. Foram registrados dois óbitos: um animal do grupo I (48 horas após a cirurgia) e um do grupo II (24 horas após a cirurgia). A causa da morte não foi determinada nos dois casos e os animais foram substituídos.

$\mathrm{Na}$ maioria dos animais as avaliações histológicas das respostas do hospedeiro ao implante foram semelhantes. Desta forma, os resultados descritivos serão apresentados em conjunto, para cada momento pós-operatório estudado, mostrando-se as diferenças individuais nas figuras e nas avaliações morfométricas.

Nos cortes histológicos observava-se a presença de uma região opticamente vazia, que correspondia à região onde se situava a esfera de PMMA, circunjacente a esta uma zona de colágeno, que correspondia às escleras utilizadas como revestimento. Externamente a esta zona de colágeno, verificava-se a presença de tecido conjuntivo, que faltava em algumas regiões. A área de colágeno apresentava fendas, provavelmente devido ao processamente histológico, verificado em todos os grupos.

No primeiro período pós-implante analisado tanto no grupo I (Figuras 2 e 3) quanto no grupo II (Figuras 4 e 5), notava-se a presença de infiltrado inflamatório predominantemente leve a moderado, com pequenas áreas de infiltrado intenso. Na região anterior, ou seja, próxima à conjuntiva, havia predominância de células polimorfonucleares, enquanto na região posterior, a predominância era de mononucleares no primeiro período após o implante. O infiltrado inflamatório foi gradativamente diminuindo ao longo dos diferentes momentos de observação.

Houve a formação de cápsula fibrosa disposta ao redor da esclera, com variabilidade de espessura e presença de neovasos, sendo mais espessa no primeiro momento e diminuindo ao longo do tempo. A estrutura mostrava-se bem preservada, apresentando alguma variabilidade de espessura.

Nas figuras 6, 7 e 8 estão representadas as escleras: não tratada, tratada com glicerina e tratada com irradiação gama, hidróxido de sódio e glicerina, processadas após receberem os respectivos tratamentos e re-hidratadas em solução fisiológica, com exceção da esclera não tratada, que foi processada imediatamente após a coleta. Nota-se na primeira as fibras de 
colágeno e fibroblastos, na segunda observa-se restos celulares e na terceira completa acelularidade. As fibras de colágeno estão preservadas, tendo um aspecto mais compacto (Figura 8), perdendo os contornos presentes na esclera não tratada (Figura 6) e na esclera preservada com glicerina (Figura 7), adquirindo um aspecto mais vítreo.

À microscopia eletrônica, observa-se na esclera não tratada estruturas cilíndricas que apresentam estriações transversais de bandas elétron densas alternadas com bandas mais claras repetitivas, características de fibrilas de colágeno (Figura 9). Na esclera tratada com glicerina (Figura 10), as estruturas cilíndricas de feixes de colágeno possuem os contornos pouco delineados e mais estreitos. Na esclera tratada com irradiação há nítida perda dos contornos dos feixes de colágeno, os quais se mostram com aspecto fragmentado, porém mantêm diâmetros semelhantes aos da esclera a fresco (Figura 11).
Não houve diferença entre os grupos no que se refere ao infiltrado inflamatório e na preservação da esclera, nos quatro períodos pós-implante estudados. A análise da vascularização da interface cirúrgica apontou uma diferença significativa entre os grupos no momento de 21 dias após o implante $(\mathrm{P}<0,001)$, tendo o grupo II apresentado uma neovascularização maior. A comparação da espessura da cápsula fibrosa apontou uma diferença significativa entre os grupos nos momentos correspondentes a 21 dias $(\mathrm{P}<0,001)$ e 42 dias $(\mathrm{P}<0,001)$, sendo que nos dois momentos o grupo II apresentou cápsula fibrosa mais espessa do que o grupo I. Houve também uma variação na espessura da esclera, sendo mais espessa no grupo II no momento pós-implante de 21 dias ( $\mathrm{P}=0,003)$ e 42 dias $(\mathrm{P}=0,024)$.

Quando a avaliação foi feita ao longo do tempo, observouse uma diminuição da vascularização da interface cirúrgica (Tabela 1) entre o momento de 7, 21, 42 e 84 dias, estatisticamente

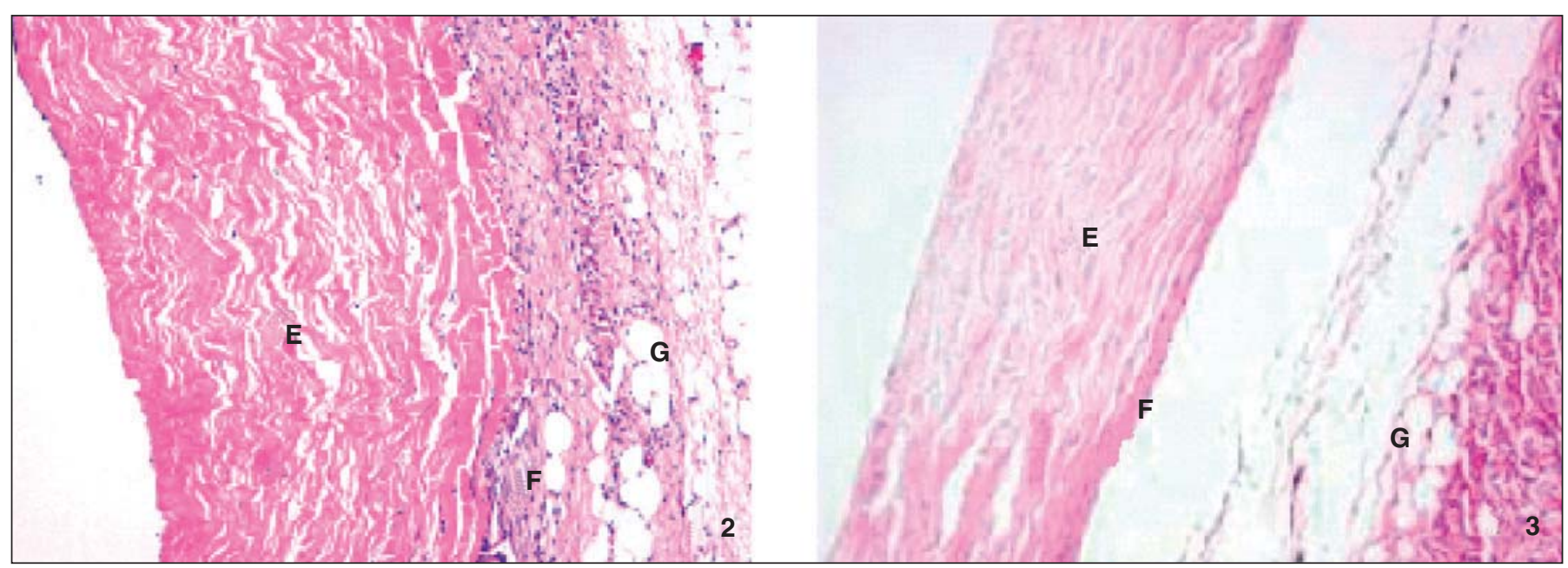

Figuras 2 e 3 - Grupo I. Fotomicrografia de corte histológico da esclera, mostrando sua estrutura bem preservada, composta por fibrilas de colágeno distribuídas em feixes (E). Presença de cápsula fibrosa (F) e tecido gorduroso (G); 7 dias após o implante (Figura 2); 84 dias após o implante (Figura 3). (HEx100)

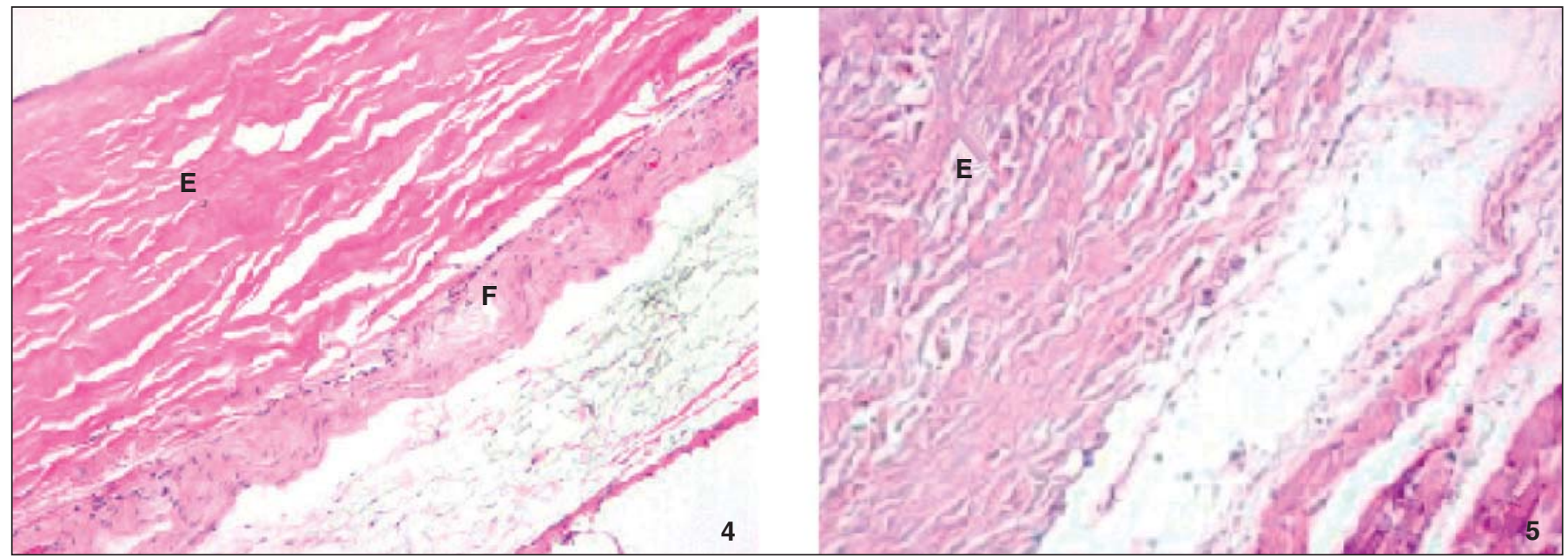

Figuras 4 e 5 - Grupo II. Fotomicrografia de corte histológico da esclera, mostrando sua estrutura bem preservada, composta de fibras colágenas, distribuídas em feixes (E). Presença de cápsula fibrosa (F) junto à esclera; 7 dias após o implante (Figura 4); 84 dias após o implante (Figura 5). (HEx100) 
644 Análise comparativa entre esclera tratada com glicerina e esclera tratada com irradiação gama, álcali e glicerina em reconstrução de cavidade anoftálmica: estudo experimental em coelhos

significativa, tanto no grupo I quanto no grupo II. A comparação entre grupos apontou uma diferença significativa somente no momento correspondente a 21 dias, após a cirurgia.

A comparação da espessura da cápsula fibrosa apresentou uma diminuição significativa a partir do momento de 42 dias, tanto no grupo I quanto no grupo II. A comparação entre os grupos apresentou diferença significativa nos momentos de 21 e 42 dias, após a cirurgia.

A comparação da espessura da esclera, dentro do mesmo grupo, apresentou uma diminuição significativa entre o momento de observação de 7 dias e 84 dias após o implante, no grupo I. A diminuição da espessura foi significativa entre 7 e 21 dias, e entre 7 e 84 dias no grupo II. A comparação entre os grupos apontou uma diferença significativa entre ambos nos momentos de 21 e 42 dias.

\section{DISCUSSÃO}

O presente estudo foi delineado, usando animais de experimentação que foram enucleados e que receberam implantes de PMMA, revestidos por esclera preservada de 2 formas diferentes: por glicerina e por irradiação gama combinada com álcali e glicerina, com o objetivo de comparar estes métodos de preservação.

A validação da descontaminação das escleras, tanto no grupo I quanto no grupo II, demonstrou que não ocorreu crescimento bacteriano. Este resultado está de acordo com os observados em um estudo em que a esclera apresentou cultura negativa após o oitavo dia de preservação em glicerina ${ }^{(11)}$, possivelmente devido a sua atividade bacteriostática ${ }^{(14-15)}$.

O álcali (hidróxido de sódio) atuou no processo de descontaminação das escleras desnaturando proteínas ${ }^{(16)}$. A irradiação gama por provocar quebras na estrutura molecular dos ácidos nucléicos (por exemplo, quebra das fitas simples ou duplas, quebra das ligações cruzadas), inativa os vírus ${ }^{(17)}$.

Comparando as escleras tratadas com irradiação gama, álcali e glicerina com esclera tratada somente com glicerina, nota-se que as primeiras estão isentas de células, tornando-as, portanto, inadequadas para a multiplicação de vírus, devido estes serem parasitas intracelulares obrigatórios. Este fato é devido ao processamento enzimático sofrido pelas escleras do grupo II, quando os elementos celulares foram removidos, permanecendo somente o colágeno e tornando-a imunogenicamente inerte, semelhante ao que ocorre no tratamento do "alloderm" humano ${ }^{(18)}$. Por outro lado o processamento enzimático provoca degradação estrutural das fibras de colágeno ${ }^{(19)}$.

No presente estudo todas as escleras avaliadas apresentavam-se bem preservadas, mantendo a integridade dos feixes de colágeno, durante todo o experimento. As escleras dos grupos I e II apresentavam-se com os contornos dos feixes de colágeno menos definidos, quando comparados ao colágeno da esclera não tratada, tanto na microscopia óptica como na eletrônica. Estas alterações, entretanto, não tiveram influência desfavorável clínica no período estudado.

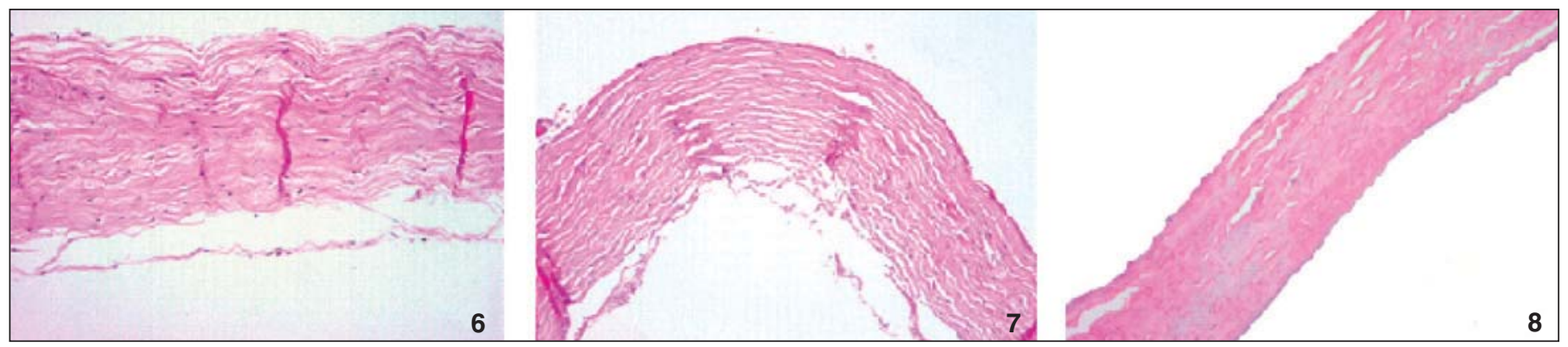

Figuras 6, 7 e 8 - Esclera não tratada, esclera tratada com glicerina e esclera tratada com irradiação gama, álcali e glicerina, respectivamente. (HEx100)
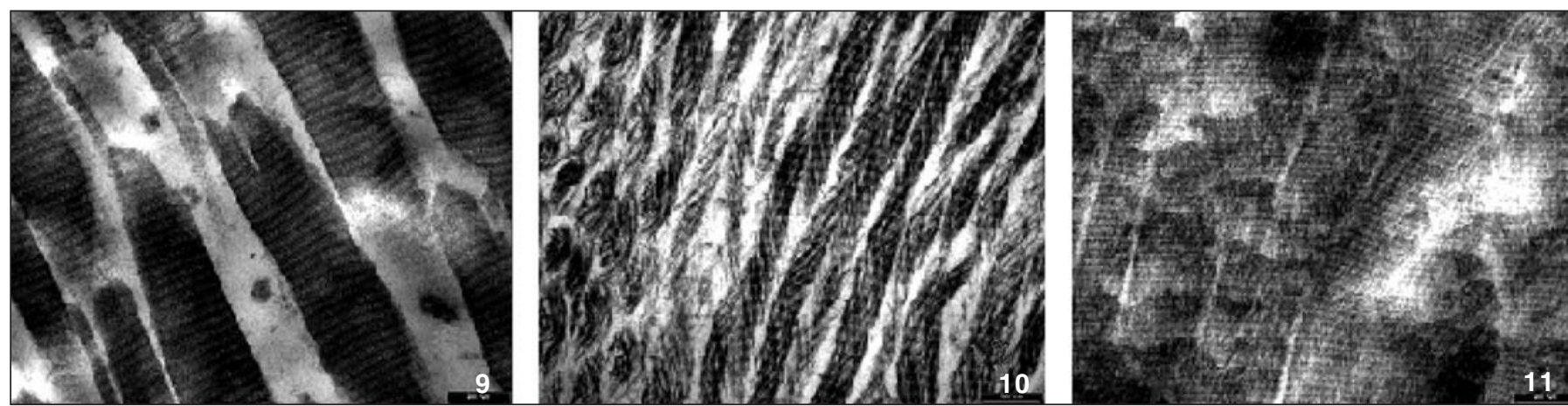

Figuras 9, 10 e 11 - Esclera não tratada, esclera tratada com glicerina e esclera tratada com irradiação gama, álcali e glicerina, respectivamente, ao microscópio eletrônico. (x39.000) 


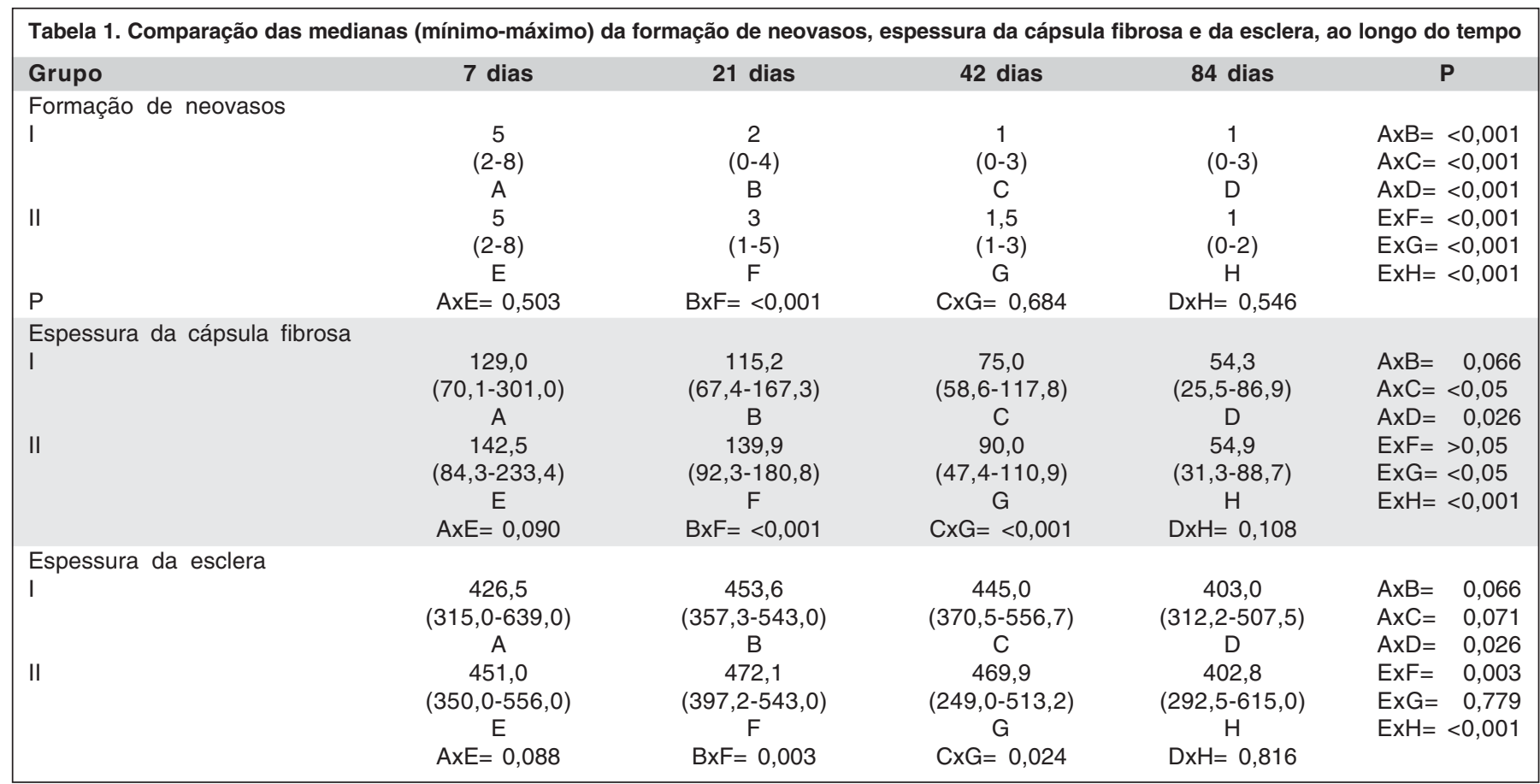

Neste estudo, observou-se que a neovascularização formada na interface cirúrgica diminuiu ao longo do tempo, tanto no grupo I quanto no grupo II. Entretanto, a vascularização foi maior no grupo II, no momento de observação de 21 dias após o implante. Os neovasos que se formam no tecido cicatricial, são altamente permeáveis às proteínas plasmáticas, processo importante para a formação de estroma para o crescimento de fibroblastos e células endoteliais ${ }^{(20-21)}$. Em estudo comparando enxertos homólogos de esclera e dura-máter em olhos de coelhos, foi observada uma diminuição gradual da vascularização no período de observação de 12 semanas ${ }^{(22)}$. A análise da vascularização ao redor de implante dérmico acelular humano e porcino no subcutâneo de $\operatorname{ratos}^{(23)}$, constatou que ao redor dos implantes humanos havia um número maior de neovasos com 7 dias que diminuiu progressivamente até o sexagésimo dia e voltou a aumentar com 180 dias. Nos implantes porcinos havia ao redor um número semelhante de neovasos em todos os momentos.

O infiltrado inflamatório foi considerado moderado nos sete primeiros dias, em ambos os grupos, constituído principalmente de células polimorfonucleares, diminuindo a partir do $21^{\circ}$ dia, apresentando maior redução entre o $42^{\circ}$ e $84^{\circ}$ dia. Em redor de cada implante existiam áreas de moderada inflamação bem como áreas de inflamação escassa, sem razões discerníveis para justificar estas diferenças. Estas áreas de variabilidade inflamatória também foram reportadas em um estudo usando o Gore-Tex como implante orbital em coelhos e enucleando-os após seis semanas $^{(24)}$.

Houve evidência de formação de cápsula fibrosa em todos os espécimes, porém esta não era homogênea quanto à espessura e estava ausente em alguns locais. Tanto no grupo I quanto no grupo II a cápsula fibrosa foi maior no momento de 7 dias, diminuindo no decorrer do tempo em ambos os grupos. O grupo II apresentou cápsula mais espessa nos momentos de 21 e 42 dias. A extensão da formação da cápsula depende de uma variedade de fatores, incluindo tamanho do implante e forma do implante ${ }^{(25)}$, textura da superfície ${ }^{(26)}$, superfície química $^{(27)}$, tamanho do poro $^{(28)}$ e local de implante ${ }^{(29)}$.

O desenvolvimento de uma cápsula fibrosa ao redor de um implante é uma resposta biológica a um corpo estranho ${ }^{(30)}$. A cápsula isola o corpo estranho do ambiente biológico para minimizar os efeitos adversos. A cápsula fibrosa rodeando os implantes caracteriza-se pela presença de macrófagos, células gigantes, linfócitos, fibroblastos e matriz densa de colágeno e tecido fibroso ${ }^{(28)}$.

A análise morfométrica das escleras indicou que houve uma diminuição na espessura no momento de observação de 84 dias nos dois grupos, quando comparada ao início, provavelmente relacionado com a reabsorção escleral associada à integração ao receptor. O grupo II apresentou um aumento da espessura da esclera quando comparado ao grupo I nos momentos de 21 e 42 dias, dados estes destoantes da evolução do experimento. A diminuição da espessura da esclera, após 84 dias, poderia representar uma leve reabsorção, estando de acordo com o estudo realizado em que o enxerto de esclera apresentou uma discreta reabsorção, somente na periferia, com formação de membrana fibrosa, integrando este à esclera do hospedeiro ${ }^{(22)}$. Um outro aspecto a ser comentado, seria o fato da esclera não apresentar uma espessura uniforme ${ }^{(31)}$ e ao analisar-se um determinado segmento microscopicamente não se tem a noção exata da topografia do mesmo. 
646 Análise comparativa entre esclera tratada com glicerina e esclera tratada com irradiação gama, álcali e glicerina em reconstrução de cavidade anoftálmica: estudo experimental em coelhos

\section{CONCLUSÃO}

Os resultados mostraram que a esclera tratada com irradiação gama, álcali e glicerina, quando utilizada como revestimento de implante de PMMA para reconstrução de cavidade anoftálmica de coelho, comportou-se de maneira similar à esclera tratada com glicerina, tradicionalmente utilizada. Comparativamente, os dois tratamentos apresentaram resposta inflamatória similar. A formação de neovasos, espessura da cápsula fibrosa e espessura da esclera evoluíram de maneiras diferentes nos dois grupos experimentais, porém apresentaram resultados similares ao final do período de observação de 84 dias. Não houve diferença significativa entre os dois grupos quanto à preservação da esclera.

\section{ABSTRACT}

Purpose: To compare two sclera decontamination methods: treatment with glycerin versus treatment with gamma irradiation, alkali and glycerin, aiming to detect the clinical and histological alterations in rabbit anophthalmic sockets reconstructed with sclera-involved polymethylmethacrylate spheres. Methods: Thirty-nine New Zealand-breed rabbits were divided into two groups: group I, whose animals were submitted to enucleation of one eye and reconstruction with a polymethylmethacrylate sphere involved in glycerin-treated sclera; group II, where there was enucleation, and reconstruction performed with a polymethylmethacrylate sphere involved in sclera treated with gamma irradiation, alkali and glycerin. The two groups were observed at four moments, at 7,21, 42 and 84 days after surgery. Preset times elapsed, the rabbits were euthanized, sockets were exenterated, the material was processed for embedment in paraffin, cut into $5 \mu \mathrm{m}$ sections thick and stained with hematoxylin-eosin and Masson's trichrome techniques. The scleras were submitted to morphometric and semiquantitative analysis. Results were compared by Mann-Whitney's non-parametric test. Results: Comparative analysis of vascularization of the surgical interface pointed out a significative difference in the evaluation done 21 days after the implant $(\mathrm{P}<0.001)$, with group II showing greater neovascularization. Comparison of the fibrous capsule thickness displayed a significative difference at moments corresponding to 21 days $(\mathrm{P}<0.001)$ and 42 days $(\mathrm{P}<0.001)$. At both moments, group II presented a thicker fibrous capsule than group I. Likewise, there was variation in sclera thickness, being thicker in group II, at the 21-day post-implant $(\mathrm{P}=0.003)$ moment, and at the 42-day moment $(\mathrm{P}=0.024)$, as well. Along the experimental period, when groups were analyzed we could observe statistically significative diminution of vascularization in the surgical interface, in group I, as well as in group II, at the moment of 7, 21, 42 and 84 days. Conclusion: When used as coating on the polymethylmethacrylate implant for the reconstruction of rabbit anophthalmic socket, the sclera treated with gamma irradiation, alkali and glycerin reacted similarly to the traditionally used glycerin-treated sclera. The two treatments induced a similar inflammatory response. The formation of neovessels, thickness of fibrous capsule and of sclera developed differently in the two groups. Nevertheless, they presented similar results at the end of the 84-day observation period. There was no significant difference between the two groups, with regard to sclera preservation.

Keywords: Sclera; Sclera/radiation effects; Decontamination; Eye enucleation; Orbital implants; Glycerol; Polymetylmethacrylate; Comparative study; Rabbits

\section{REFERÊNCIAS}

1. Soares EJ. Prevenção das deformidades órbito palpebrais das cavidades anoftálmicas. 20 anos de experiência. Rev Bras Oftalmol. 1990;49(3):185-91.

2. Schimmelpfennig B, Hurzeler R. Bacterial flora of stored human donor corneas after antibiotic treatment. Albrecht Von Graefes Arch Klin Exp Ophthalmol. 1977;202(3):181-5

3. Leveille AS, McMullan FD, Cavanagh HD. Endophthalmitis following penetrating keratoplasty. Ophthalmology. 1983;90(1):38-9.

4. Badenoch PR, Alfrich SJ, Wedding TR, Coster DJ. Effectiveness of a decontamination method for donor corneas. Brit J Ophthalmol. 1988;72(3):225-7.

5. Brown P, Gibbs CJ Jr, Amyx HL, Kinsgsbury DT, Rohwer RG, Sulima MP, et al. Chemical disinfection of Creutzfeldt-Jakob disease virus. N Engl J Méd. 1982;306(21):1279-82.

6. Diringer H, Braig HR. Infectivity of unconventional viruses in dura-mater. Lancet. 1989;25(8635):439-40.

7. Taylor DM. Inactivation of transmissible degenerative encephalopathy agents a review. Vet J. 2000;159(1):10-7. Comment in: Vet J. 2000;159(1):3-4.

8. Colvard M, Waller RR, Campbell J, Friedt R. Sterilization of scleral homografts with ionizing irradiation. Am J Ophtalmol. 1979;87(4):494-6.

9. Rosenwasser GO, Janes RL, Greene WH. Recovery of herpes simplex virus from preserved sclera [abstract]. Invest Ophthalmol Vis Sci. 1993;34:1494.

10. Seiff SR, Chang JS, Hurt MH, Khayam-Bashi H. Polymerase chain reaction identification of human immunodeficiency virus-1 in preserved human sclera. Am J Ophthalmol. 1994;118(4):528-30.

11. Dailey JR, Rosenwasser GO. Viability of bacteria in glycerin and ethanol preserved sclera. J Refract Corneal Surg. 1994;10(1):38-40.

12. Lucci LM. Estudo in vitro da descontaminação da sclera humana [tese]. São Paulo; Universidade Federal de São Paulo; 1998.

13. National Research Council: Guide for the care and use of Laboratory Animals. Washington: National Academic Press. 1996. p.130.

14. de Backere AC. Euro Skin Bank: large scale skin-banking in Europe based on glycerol-preservation of donor skin. Burns. 1994;20(Supp 1):S4-9.

15. Hoekstra MJ, Kreis RW, Du Pont JS. History of the Euro Skin Bank: the innovation of preservation technologies. Burns. 1994;20(Supp 1):S43-7.

16. Nelson DL, Cox MM. Lehninger: princípios de bioquímica. São Paulo: Sarvier; 2004

17. Thomas FC, Davies AG, Dulac GC, Willis NG, Papp-Vid G, Girard A. Gamma ray inactivation of some animal viruses. Can J Comp Med. 1981;45(4):397-9.

18. Shorr N, Perry JD, Goldberg RA, Hoenig J, Shorr J. The safety and applications of acellular human dermal allograft in ophthalmic plastic and reconstructive surgery. Ophthal Plast Reconstr Surg. 2000;16(3):223-30.

19. Sclafani AP, McCornick SA, Cocker R. Biophysical and microscopic analysis of homologous dermal and fascial materials for facial aesthetic and reconstructive uses. Arch Facial Plast Surg. 2002;4(3):164-71.

20. Goldberg RA, Holds JB, Ebrahimpour J. Exposed hydroxyapatite orbital implants. Report of six cases. Ophthalmology. 1992;99(5):831-6.

21. Cotran KS, Kumar V, Robbins SL. Patologia estrutural e funcional. Rio de Janeiro: Guanabara-Koogan, 2000.

22. Araf D. Enxertos homólogos de esclera e dura-máter em olhos de coelhos: análise histopatológica comparativa [tese]. São Paulo: Universidade de São Paulo; 2004

23. Hoyama E. Implante dérmico acelular humano e porcino no subcutâneo do rato. Estudo clínico, morfológico e morfométrico. [Tese]. Botucatu: Universidade Estadual Paulista; 2002.

24. Dei Cas R, Maus M, Bilyk J, Chang W, Eagle RC Jr, Rubin P. Gore-Tex as an orbital implant material. Ophthal Plast Reconstr Surg. 1998;14(6):425-31. 
Análise comparativa entre esclera tratada com glicerina e esclera tratada com irradiação gama, álcali e glicerina em

25. Wood NK, Kamikniski EJ, Oglesby J. The significance of implant shape in experimental testing of biological materials: disc vs rod. J Biomed Mater Res. 1970;4(1):1-12.

26. Taylor SR, Gibbons DF. Effect of surface texture on the soft tissue response to polymer implants. J Biomed Mater Res. 1983;17(2):205-27.

27. Behling CA, Spector M. Quantitative characterization of cells at the interface of long-term implants of selected polymers. J Biomed Mater Res. 1986;20(5):653-6. 28. White RA, Hirose FM, Sproat RW. Lawrence RS, Nelson RJ. Histopatho- logic observations after short-term implantation of two porous elastomers in dogs. Biomaterials. 1981;2(3):171-6.

29. Coleman DL, King RN, Andrade JD. The foreign body reaction: A chronic inflammatory response. J Biomed Mater Res. 1974;8(5):199-211.

30. Schellini SA. Avaliação da integração de esferas de hidroxiapatita sintética e de polietileno poroso em cavidades evisceradas de coelho [tese]. Botucatu: Universidade Estadual Paulista; 1999.

31. Prince JH. The rabbit in eye research. Springfield: Charles C. Thomas; 1964. 